\title{
Evidence of 2,7/2,8-dibenzodichloro- $p$-dioxin as a photodegradation product of triclosan in water and wastewater samples
}

\author{
Milagros Mezcua, M. José Gómez, Imma Ferrer, Ana Aguera, M. Dolores Hernando, \\ Amadeo R. Fernández-Alba* \\ Pesticide Residue Research Group, University of Almería, 04071 Almería, Spain
}

Received 5 December 2003; accepted 17 May 2004

Available online 28 July 2004

\begin{abstract}
A photodegradation study of triclosan, a commonly used antimicrobial agent, was carried out in order to investigate the formation of dibenzodichlorodioxin as a by-product of photodegradation in various environmental matrices and under different conditions. Deionized water and wastewater samples, spiked at $8 \mu \mathrm{g} / \mathrm{mL}$ with triclosan, were irradiated with natural sunlight. Aliquots of the spiked water samples were taken at different times of irradiation and compounds were isolated from the water samples by solid-phase extraction. Separation and detection of the compounds and degradation products was accomplished by gas chromatography-mass spectrometry. A major photolysis degradation product of triclosan, 2,7/2,8-dibenzodichloro- $p$-dioxin, was identified in wastewater samples. The photolysis experiment showed the simultaneous disappearance of triclosan and the appearance of the dioxin dependent on the $\mathrm{pH}$ and the organic matter content. Furthermore, a pilot survey monitoring for influent and effluent waters from a wastewater treatment plant was carried out. The presence of triclosan in all wastewater samples analyzed was revealed and dioxin was found in $80 \%$ of the cases, in influents and effluents, thus indicating its input and persistence through the wastewater treatment process. This represents a major finding since dioxins are more toxic than triclosan. Moreover, the presence of such compounds in wastewaters revealed the immediate need to improve the "classical" water treatment techniques, as well as considering limitation in water re-use.
\end{abstract}

(C) 2004 Elsevier B.V. All rights reserved.

Keywords: Triclosan; 2,7/2,8-Dibenzodichloro-p-dioxin; Photodegradation; GC-MS; Water; Waste water

\section{Introduction}

Triclosan is a broad-spectrum antibacterial and preservative agent widely used in personal care products [1] and also suitable for its incorporation in polymers and fibers to give these materials antibacterial properties. In cosmetic products such as soaps, shampoos, deodorants etc., its concentration is typically in the range of $0.1-0.3 \%$ [2]. As a consequence of its relatively high solubility in water $\left(10 \mathrm{mg} \mathrm{L}^{-1}\right.$ at $\left.20^{\circ} \mathrm{C}\right)$, the main route by which this compound enters in the environment is in personal care and other consumer products that are washed down the drain during normal use. Its presence in waters and wastewaters has been recently reported in the US and Europe in a very high percentages of the streams

\footnotetext{
* Corresponding author.

E-mail address: amadeo@ual.es (A.R. Fernández-Alba).
}

tested $(>50 \%)$ [3-6]. This can yield serious environmental implications as a consequence of its toxicity to water living organisms [7], resistance mechanisms in bacteria, as well as the estrogenic effects observed $[8,9]$. Furthermore, interactivity enhanced toxicity has been observed in water between triclosan and other commonly present contaminants [10].

In general, the photodegradation of triclosan to dioxins represents the main focus of environmental concern in the fate of this widespread compound [11]. It has been hypothesized that the presence of these toxic chemical compounds is derived from its synthesis [12] and also by intermolecular photochemical substitution reaction [13,14]. However, there is a controversy about the reliability of this fact and the real influence in water and wastewater environmental conditions.

In the present paper, we have studied the photochemical transformation of triclosan into dioxins under sunlight radiation at different $\mathrm{pH}$ values in water and wastewater types to get an evidence about its pre-dioxin capacity. Furthermore, 
we have monitored wastewaters (influent and effluent) from an urban treatment plant to evaluate the presence of these compounds as well as the capacity of the sewage treatment plants the elimination/removal of these contaminants.

\section{Experimental}

\subsection{Standards and reagents}

Triclosan (2,4,4'-trichloro-2'-hydroxydiphenyl ether) (97\%) and the 2,7/2,8-dichlorodibenzo-p-dioxin (99\%) isomer pair, were obtained from Aldrich (Milwaukee, WI) and LGC Promochem (USA), respectively. Pesticide-grade ethyl acetate was from Panreac (Barcelona, Spain) and methanol from Merck (Darmstadt, Germany). Oasis ${ }^{\mathrm{TM}}$ HLB (200 mg, 6cc) cartridges were obtained from Waters (Ireland). Solid-phase extraction of wastewater samples was carried out in an automated sample preparation with extraction columns system (ASPEC XL) from Gilson (Villiers-le-Bel, France).

\subsection{Chromatographic determinations}

Gas chromatography-mass spectrometry (GC-MS) analyses were run on a HP 6890 series gas chromatograph (Hewlett-Packard, Palo Alto, CA) interfaced to a HP 5973 mass-selective detector. Data acquisition and processing, and instrumental control were performed by the HP MSD Chem-Station software. Analytes were separated in a Hewlett-Packard HP-5MS capillary column (5\% biphenyl $/ 95 \%$ dimethylsiloxane), $30 \mathrm{~m} \times 0.25 \mathrm{~mm}$ i.d., $0.25 \mu \mathrm{m}$ film thickness. A split/splitless injector was used in the pulse splitless mode. An empty liner was filled with $0.5 \mathrm{~cm}$ Carbofrit (Restek, Bellefonte, CA) placed $3.6 \mathrm{~cm}$ from the upper part of the liner. The injector operating conditions were as follows: injection volume $10 \mu \mathrm{L}$; injector temperature $250^{\circ} \mathrm{C}$; initial pulse pressure $30 \mathrm{psi}(1.5 \mathrm{~min})$. The helium carrier gas flow was maintained at $1 \mathrm{~mL} \mathrm{~min}^{-1}$. The oven temperature programme was $1.0 \mathrm{~min}$ at $105^{\circ} \mathrm{C}$, $22^{\circ} \mathrm{C} \mathrm{min}^{-1}$ to $180^{\circ} \mathrm{C}, 6^{\circ} \mathrm{C} \mathrm{min}^{-1}$ to $230^{\circ} \mathrm{C}(3 \mathrm{~min})$. The transfer line temperature was set at $280^{\circ} \mathrm{C}$.

Typical MS operating conditions were optimized with the autotuning software. Electron impact (EI) mass spectra were obtained at $70 \mathrm{eV}$ electron energy and monitored from $\mathrm{m} / \mathrm{z}$ 50 to 400 . The ion source and quadrupole analyzer temperatures were fixed at $230^{\circ} \mathrm{C}$ and $106^{\circ} \mathrm{C}$, respectively. The autotuning software performed the reagent gas flow adjustment and the lens and electronic tuning.

\subsection{Photolysis experiments}

All photolysis tests were performed in 5-L Pyrex bottles (UV transmission $>80 \%$ between $320 \mathrm{~nm}$ and $400 \mathrm{~nm}$, internal diameter $18 \mathrm{~cm}$ ) and stoppered to avoid sample contamination and evaporation. Continuous agitation (magnetic stirring) was maintained during all the tests. The maximum temperature inside the beakers was $35^{\circ} \mathrm{C}$. At the beginning of the experiments, and with the bottles stoppered, the chemicals were added and mixed until a constant concentration was achieved. Afterwards, the stopper was removed and samples $(125 \mathrm{~mL})$ were collected at predetermined times. For the test performed with raw water, tap water from the Plataforma Solar de Almería was used. The most important characteristics of this water were: conductivity $0.85 \mathrm{mS}, \mathrm{CO}_{3}{ }^{2-} / \mathrm{HCO}_{3}{ }^{-} 49 \mathrm{mg} \mathrm{L}^{-1}$ (as carbon), $\mathrm{pH} 7.7$, $\mathrm{Cl}^{-} 110 \mathrm{mg} \mathrm{L}^{-1}$ and $\mathrm{SO}_{4}{ }^{2-} 80 \mathrm{mg} \mathrm{L}^{-1}$. Total organic carbon (TOC) was determined by direct infection of the filtered samples into a Shimadzu-5050A TOC analyzer, calibrated with standard solutions of hydrogen potassium phthalate.

\subsection{Collection, preparation and extraction of wastewater samples}

Wastewater samples were collected from an urban wastewater treatment plant (UWWTP) located in Almería (Spain). In this plant, the water is subjected to a primary treatment for solids removal followed by aerobic digestion. Influent and effluent water samples were collected during a sampling period of seven months, from June 2002 to March 2003. Pyrex amber glass containers previously rinsed with tap water and high-purity water $(750 \mathrm{~mL})$ were used for this purpose. All wastewater samples were filtered in the laboratory with high-pressure filtration equipment using pure cellulose membrane filters Albet ${ }^{\mathrm{R}}$ (pore size $0.45 \mu \mathrm{m}$; diameter $9 \mathrm{~cm}$; Filalbet, S.L.) and stored at $4{ }^{\circ} \mathrm{C}$ in the dark overnight until analysed. Aliquots of the filtered wastewater samples were extracted by solid-phase extraction using Oasis ${ }^{\mathrm{TM}}$

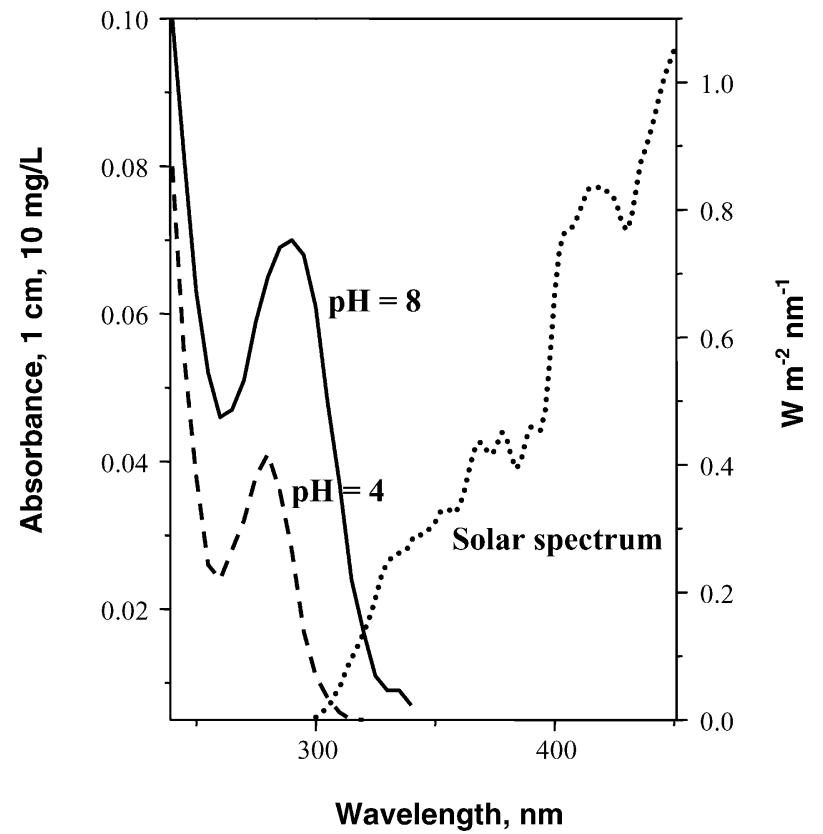

Fig. 1. UV solar spectrum and UV spectra for triclosan at two different $\mathrm{pH}$ values. 
HLB (divinylbenzene/ $N$-vinylpyrrolidone copolymer). Extractions were carried out with an automatic extraction system (ASPEC) following a similar scheme. A conditioning step was performed with methanol $(5 \mathrm{~mL})+$ distilled water $(4 \mathrm{~mL})$ at $9 \mathrm{~mL} \mathrm{~min}^{-1}$. After the conditioning step, aliquots of $50 \mathrm{~mL}$ of the filtered water samples were injected at a flow rate of $10 \mathrm{~mL} \mathrm{~min}^{-1}$. The elution step was performed with $2 \times 4 \mathrm{~mL}$ of methanol $\left(1 \mathrm{~mL} \mathrm{~min}^{-1}\right)$. The eluates obtained were concentrated to dryness by solvent evaporation with a gentle nitrogen stream and recomposed to a final volume of $1 \mathrm{~mL}$ in ethyl acetate prior to injection into the GC system.

\subsection{Recovery experiments}

The sample enrichment procedure on OasisTM HLB cartridges was controlled by systematic recovery experiments. For this purpose, volumes of $1 \mathrm{~L}$ of water and wastewater samples were spiked with known amounts of triclosan and dioxin (fortification level of 10 and $1 \mu \mathrm{g} \mathrm{kg}^{-1}$ ). The extraction and conditioning steps were performed following the procedure described above. The recovery experiments were performed using previously analyzed wastewater samples that contained concentrations of triclosan and the 2,7/2,8-dichlorodibenzo-p-dioxin (99\%) isomer pair each below $0.5 \mu \mathrm{g} \mathrm{L}^{-1}$. Results obtained after the analysis of the spiked samples were corrected with the initial concentrations present in the samples. The recoveries for triclosan and 2,7/2,8-dichlorodibenzo- $p$-dioxin were $80 \%$ and the relative standard deviation averaged $9 \%$ for both compounds.

\subsection{Extraction of particulate matter}

The retained particulated matter the filters was extracted by ultrasonication (ultrasonic bath RK-156, Bandelin, Berlin). Prior to the extraction procedure, the filters were dried at room temperature and weighed. The particulated

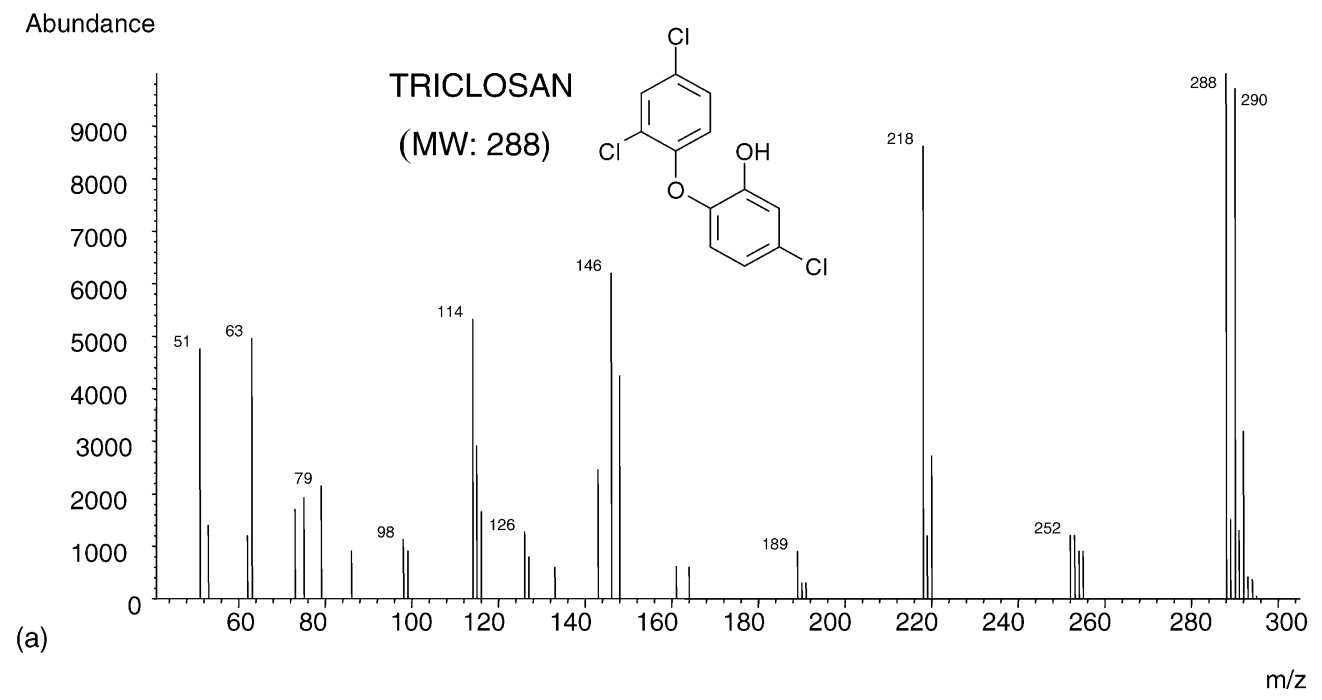

Abundance

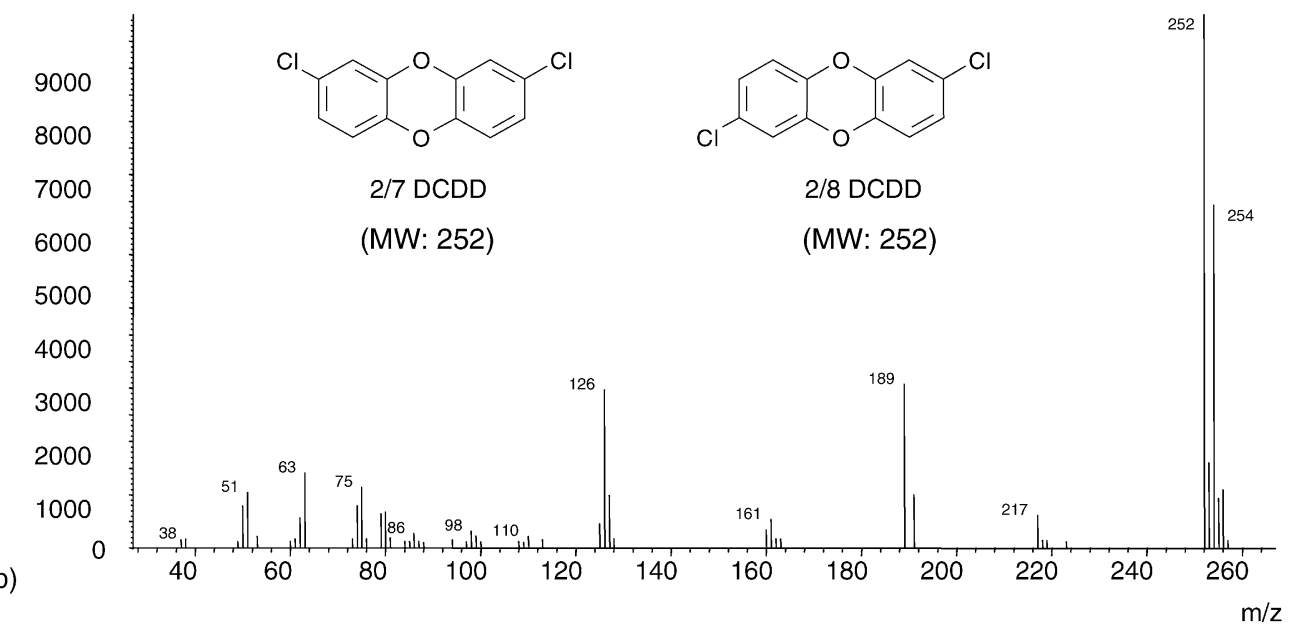

Fig. 2. Mass spectrum corresponding to: (a) triclosan and (b) 2,7/2,8-dibenzodichloro-p-dioxin (DCDD). 


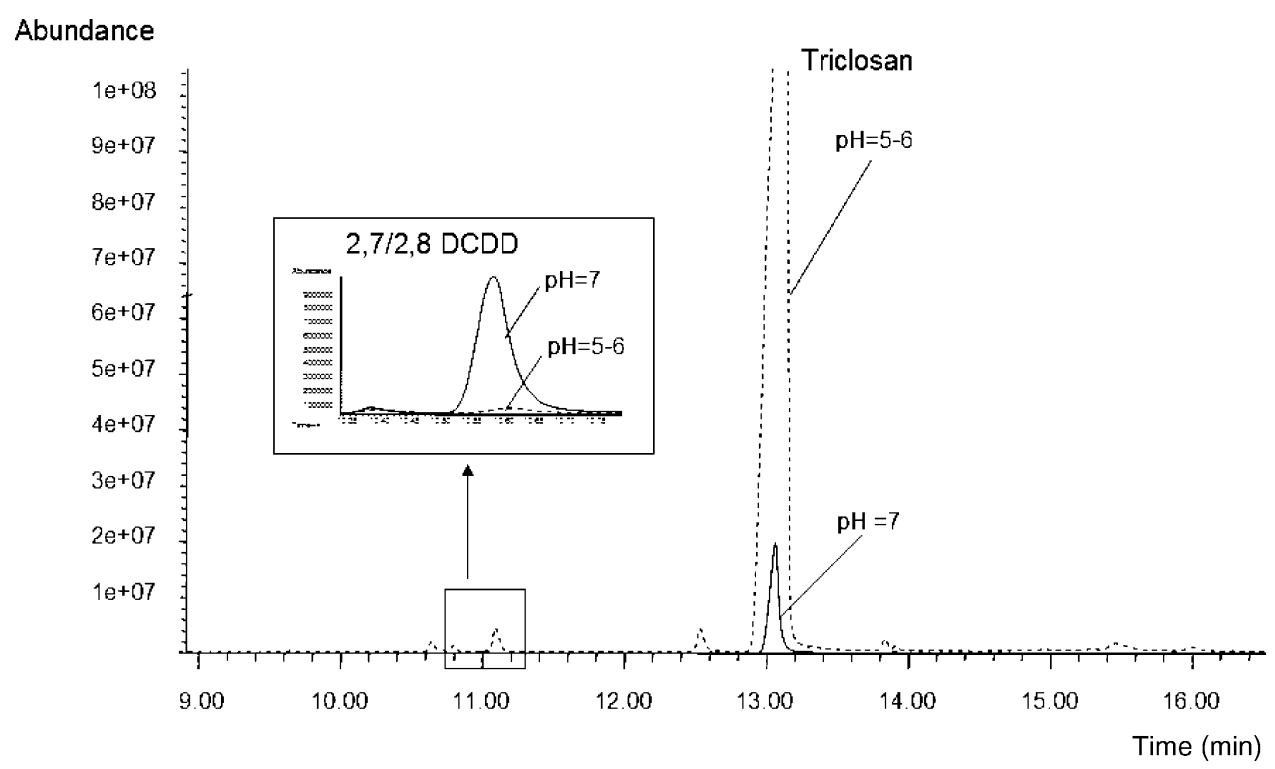

Fig. 3. Gas chromatogram corresponding to the analysis of a reagent water sample fortified with triclosan after $36 \mathrm{~h}$ of solar irradiation. Two different $\mathrm{pH}$ values (5 and 7) are compared and overlapped.

matter was extracted with $50 \mathrm{~mL}$ of ethyl acetate by ultrasonication for $30 \mathrm{~min}$. This period of extraction was selected as the best choice after several extractions were performed for different times. After extraction, aliquots of $40 \mathrm{~mL}$ of solvent were evaporated with a gentle nitrogen stream to give a final volume of $1 \mathrm{~mL}$ for GC-MS analysis.

\section{Results and discussion}

\subsection{UV spectral analyses}

Fig. 1 shows the UV spectra of triclosan at two different $\mathrm{pH}$ values, as well as the solar spectrum (altitude $500 \mathrm{~m}$, latitude $37^{\circ} \mathrm{N}$, longitude $24^{\circ} \mathrm{W}$ ). Triclosan presents a charac- teristic UV spectrum, showing a maximum around $280 \mathrm{~nm}$ and $290 \mathrm{~nm}$ at $\mathrm{pH} 4$ and $\mathrm{pH} 10$, respectively. As can be seen in this figure, the area overlapped with the solar spectrum increased considerably with increase of $\mathrm{pH}$, thus indicating a potential degradation of this compound by solar light at high $\mathrm{pH}$ values. It was then hypothesized that the interaction of solar photons with the chemical structure of the compound would allow the potential photodegradation of triclosan.

\section{2. $G C-M S$ analyses}

Gas chromatography-mass spectrometry analyses under electron impact ionization were applied for the identification of triclosan and 2,7/2,8-dibenzodichloro- $p$-dioxin [4]. The triclosan GC/EI/MS spectrum is shown in Fig. 2a. The

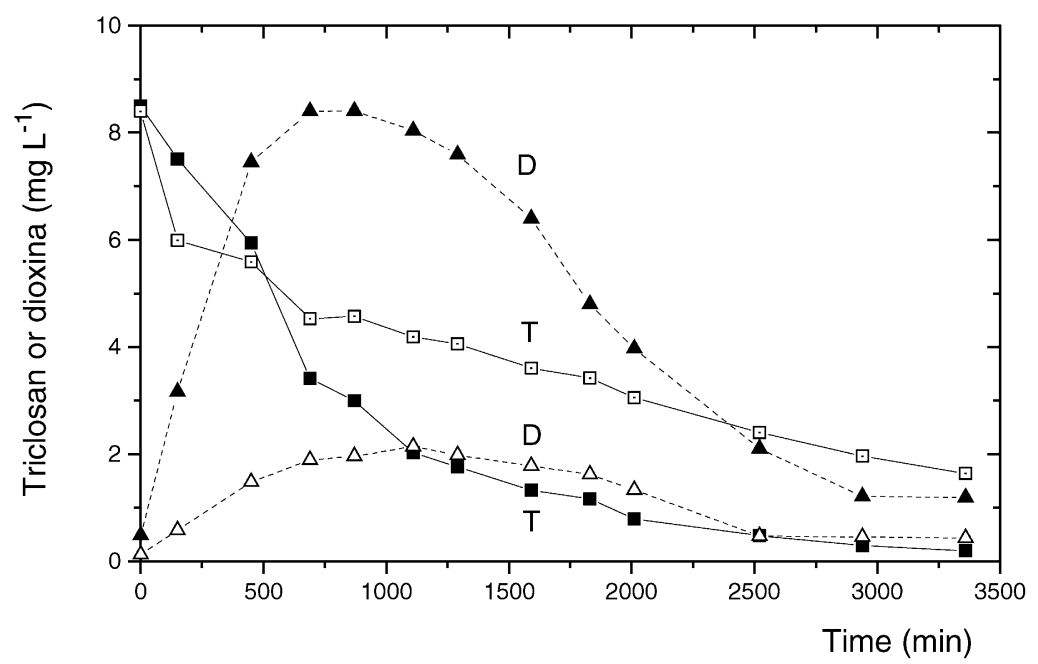

Fig. 4. Evolution of the levels of triclosan (T, open symbols) and 2,7/2,8-dibenzodichloro-p-dioxin (D, solid symbols) in reagent water and wastewater. 


\section{Abundance}

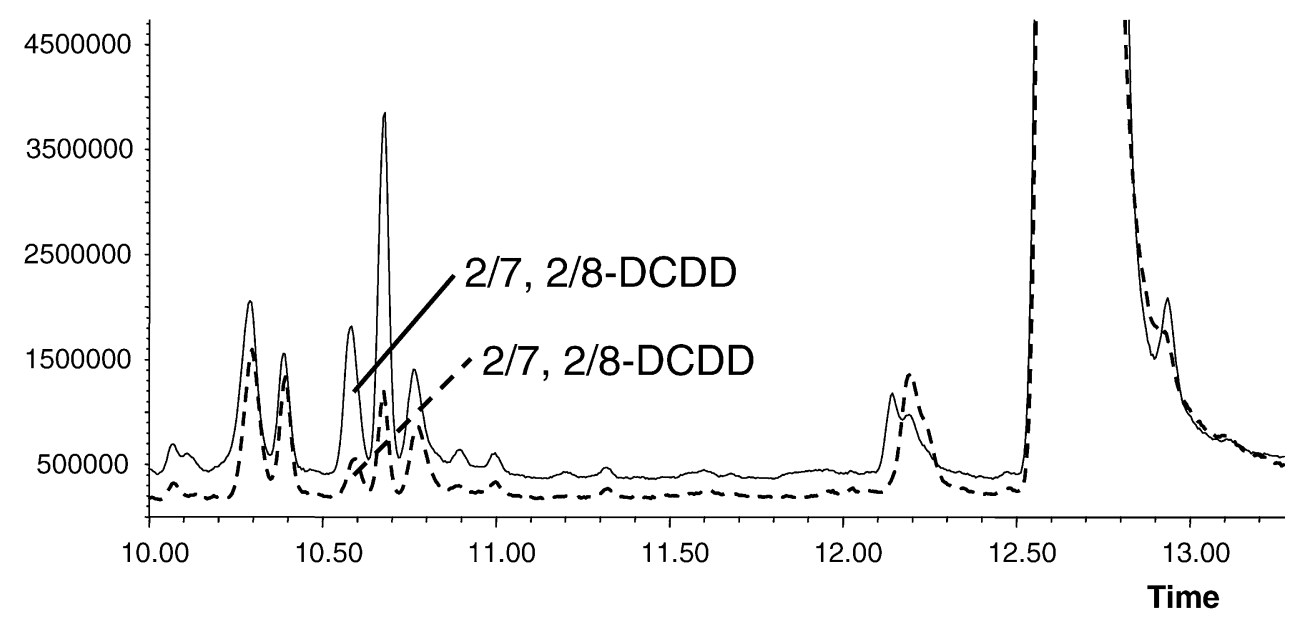

Fig. 5. Gas chromatogram corresponding to the analysis of a reagent water (solid line) and a wastewater sample (dotted line) fortified with triclosan after $11 \mathrm{~h}$ of solar irradiation. 2,7/2,8-Dibenzodichloro-p-dioxin (DCDD) peak is shown.

base peak ions are $m / z 288$ and 290 , corresponding to the molecular ions $[M]^{+}$and $[M+2]^{+}$, presenting the characteristic chlorine signature. The major fragmentation ion is $\mathrm{m} / \mathrm{z} 218$ and it corresponds to the loss of two chlorine atoms. These three ions with consistent relative abundances were monitored in subsequent experiments under selected ion monitoring (SIM) conditions. Fig. 2b shows the 2,7/2,8-dibenzodichloro- $p$-dioxin GC/EI/MS spectrum. The base peak ions in this case are $m / z 252$ and 254, corresponding to the molecular ions $[M]^{+}$and $[M+2]^{+}$, also presenting the chlorine signature. The fragmentation ion corresponds to $\mathrm{m} / \mathrm{z} 189$ and it is formed after the loss of a chlorine atom and an ethyl group in the molecule. Thus, these three ions with consistent relative abundances were the ones chosen for further analyses under SIM conditions.

\subsection{Photolysis experiment}

\subsection{1. $p H$ influence}

As described in the previous section, a difference in the UV spectrum for triclosan was observed at different $\mathrm{pH}$ values. The area overlaying the solar spectrum occurred at a higher $\mathrm{pH}$. For this reason, two experiments of photodegradation at two different $\mathrm{pH}$ values 5 and 7 , were performed using distilled water as a matrix. Triclosan was spiked in reagent water at a concentration of $8.2 \mathrm{mg} \mathrm{L}^{-1}$, and solar light irradiated the water samples. Triclosan concentrations were monitored at different times during the experiment. Fig. 3 shows the chromatogram corresponding to the analysis of the reagent water spiked with triclosan after $36 \mathrm{~h}$ of solar irradiation. Triclosan was degraded only at the higher

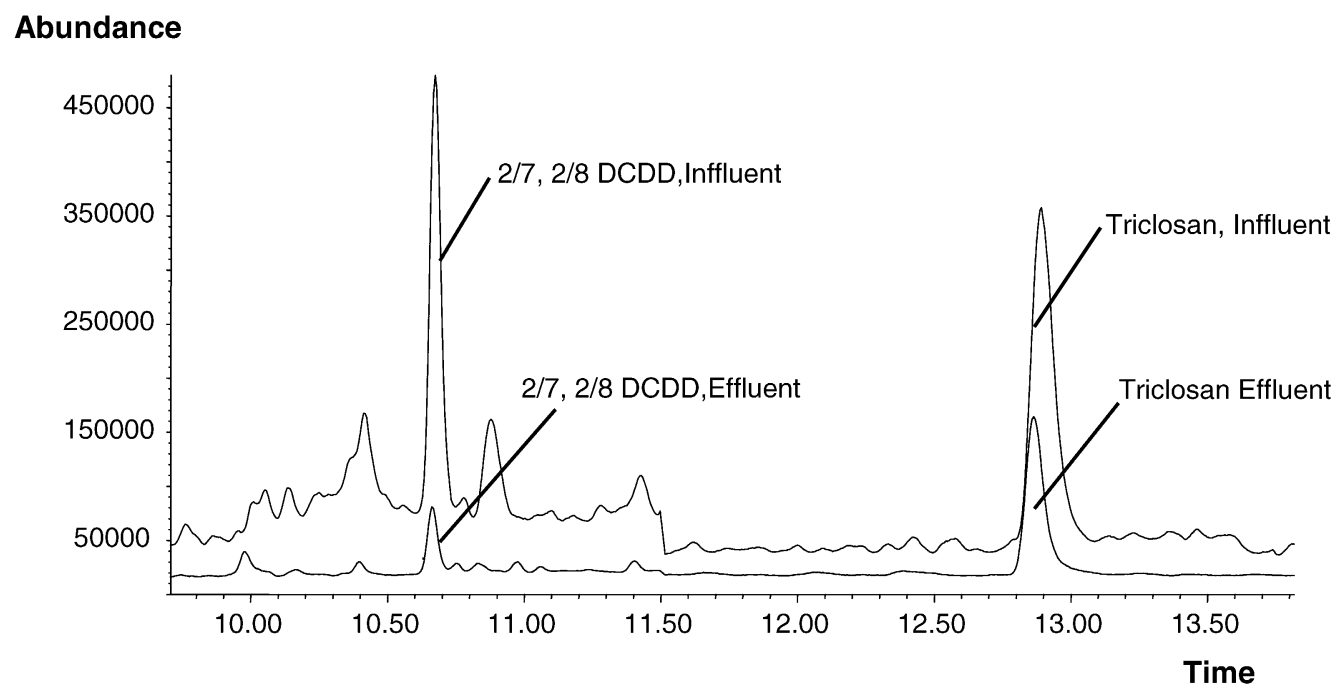

Fig. 6. Gas chromatograms corresponding to influent and effluent waste water samples collected from a treatment plant in El Ejido (Alméria, Spain). Influent and effluent response are compared for triclosan and 2,7/2,8-dibenzodichloro-p-dioxin (DCDD). 
$\mathrm{pH}$, into dioxin, as can be observed in this figure. This result was in accordance with the hypothesis postulated in the previous section, in relation to the overlapping of the UV spectra of triclosan and solar light. The Dioxin was found as a major degradation product of triclosan at a high $\mathrm{pH}$ and the identification was successful by GC-MS.

\subsubsection{Matrix influence}

A second photolysis degradation experiment was carried out comparing two different matrices of water. For this, reagent water $(\mathrm{pH} 7)$ and wastewater $(\mathrm{pH} 8)$ were spiked with triclosan at $8.1 \mathrm{mg} \mathrm{L}^{-1}$ and irradiated by solar light. Concentrations for triclosan and 2,7/2,8-dibenzodichloro- $p$-dioxin were recorded at different times. The result of this experiment is shown in Fig. 4. The disappearance of triclosan is much faster in wastewater as compared to reagent water. In this way, the rapid formation of 2,7/2,8-dibenzodichloro- $p$-dioxin is observed. The dioxin reaches a maximum after $1000 \mathrm{~min}$ of irradiation and it further degrades to a minimum after $3500 \mathrm{~min}$ in wastewater samples. In contrast, the experiment performed with reagent water showed a less significant degradation, as expected from the previous experiment at $\mathrm{pH}$ 7. This is an important result, since it shows the formation of 2,7/2,8-dibenzodichloro- $p$-dioxin under environmental conditions (Fig. 5).

\subsection{Pilot survey analyses}

\subsubsection{Influent and effluent samples}

In order to evaluate the significance of the dioxin formation in wastewaters, monitoring of triclosan and 2,7/2,8-dibenzodichloro- $p$-dioxin in influent and effluent samples from a wastewater treatment plant was carried out over 1 year (see Table 1). Common physicochemical parameters were evaluated in the wastewater samples. TOC, conductivity and $\mathrm{pH}$ were determined in influent and effluent samples. Mean conductivity values for influents and effluents were $1978.4 \mu \mathrm{S} \mathrm{cm}^{-1}$ and $1480.2 \mu \mathrm{S} \mathrm{cm}^{-1}$, respectively. Measurements of TOC were on average between $96.8 \mathrm{mg} \mathrm{L}^{-1}$ and $22.7 \mathrm{mg} \mathrm{L}^{-1}$ for influent and effluent, respectively. This means that a significant decrease of $76.5 \%$ occurs in the treated wastewaters. No significant differences were found in the $\mathrm{pH}$ measurements, being in the range 7-8 for all the wastewater samples.

Concentrations for triclosan and 2,7/2,8-dibenzodicholoro- $p$-dioxin were monitored for influent and effluent samples from the wastewater treatment plant. As can be observed in Table 1, the concentrations of these two compounds in the effluent waters were lower than in the influent waters, as expected by the removal of these compounds in the treatment plant. However, total elimination was not observed. The highest concentrations found for triclosan and the dioxin were those corresponding to the months of January, February and June. Fig. 6 shows the chromatogram corresponding to the analysis of a wastewater sample in March. The

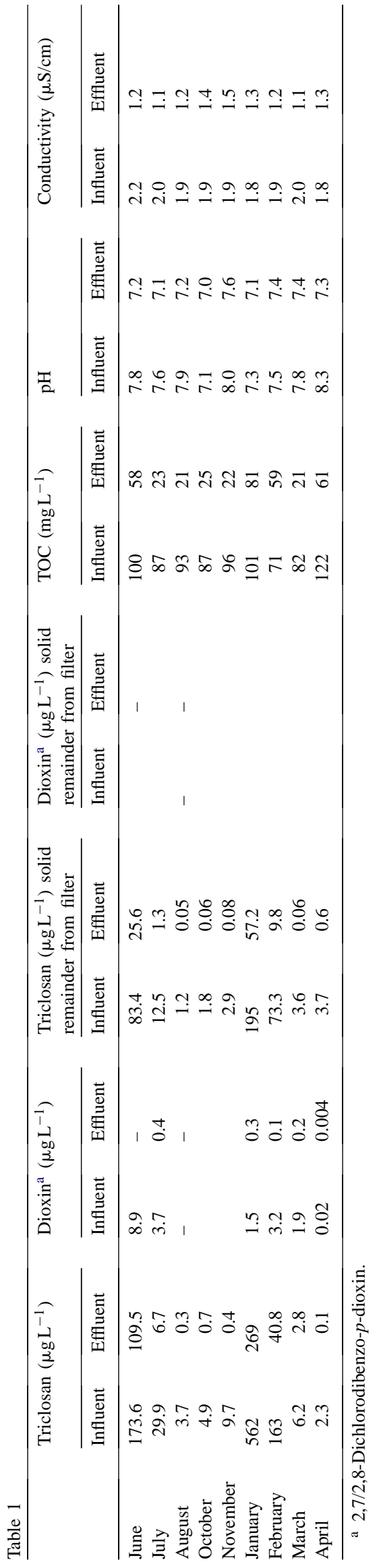


effluent and the influent results are compared in this figure, showing a major concentration in influent samples.

\subsubsection{Particulate matter}

Only triclosan was found in the particulate matter samples from the filter. The $K_{\text {ow }}$ value for this compound is relatively high, thus being more hydrophobic and susceptible to being adsorbed by particulate matter. This result reflects the affinity of triclosan for solids and preferential partitioning to particulate matter and sediment in the aquatic environment. The dioxin was not observed in the particulate matter samples, indicating its higher affinity for water. However, no fortification experiment were carried out on this type of matrix and it is possible that the extraction of the dioxin is not efficient enough or the levels are lower than the detection limit. Future work will be done in order to investigate the fate and behavior of this degradation product in environmental samples.

To our knowledge, this is the first time that a photodegradation study for triclosan has been carried out in wastewater samples. Studies of photodegradation are important in order to understand the fate of new organic compounds released into the environment. Not only is the presence of the target compound an important issue of knowledge but also that of possible degradation by-products, which can be even more toxic and persistent than parent compounds.

\section{References}

[1] Council Directive 76/768/EEC on the Approximation of the Laws of the Member States Relating to Cosmetic Products, European Commission, Brussels, Belgium, 1999.

[2] D. Sabaliunas, S. Webb, A. Hauk, M. Jacob, W. Eckhoff, Water Res. 37 (2003) 3145-3154.

[3] D.W. Kolpin, E.T. Furlong, M.T. Meyer, E.M. Thurman, S.D. Zaugg, L.B. Barber, H.T. Buxton, Environ. Sci. Technol. 36 (2002) 1202.

[4] A. Aguera, A. Fernandez-Alba, L. Piedra, M. Mezcua, M.J. Gomez, Anal. Chim. Acta 480 (2003) 193-205.

[5] H. Singer, S. Muller, C. Tixier, L. Pillonel, Environ. Sci. Technol. 36 (2002) 4998-5004.

[6] A. Lindstrom, I.J. Buerge, T. Poiger, M.D. Muller, P.-A. Bergqvist, H.R. Buser, Environ. Sci. Technol. 36 (2002) 2322-2329.

[7] M. Adolfsson-Erici, M. Pettersson, J. Parkkonon, J. Sturve, Chemosphere 46 (2002) 1485-1489.

[8] A.D. Russell, J. Appl. Microbiol. 92 (2002) 121S-135S

[9] A.P. van Wezel, T. Jager, Chemosphere 47 (2002) 113-1128.

[10] M.D. Hernando, A.R. Fernandez-Alba, R. Tauler, D. Barcelo, Talanta, in press, 2004.

[11] C. Tixier, H.P. Singer, S. Canonica, S.R. Muller, Environ. Sci. Technol. 36 (2002) 3482-3489.

[12] J. Menoutis, A.I. Parisi, Technology Review Series, Quantex Laboratories, 2002, http://www.quantexlabs.com/triclosan.htm.

[13] D.E. Latch, J.L. Packer, W.A. Arnold, K. McNeill, J. Photochem. Photobiol. A 158 (2003) 63-66.

[14] T. Okumura, Y. Nishikawa, Anal. Chim. Acta 325 (1996) 175184. 